\title{
Microhydration of Protonated Nucleic Acid Bases and Protonated Nucleosides in the Gas Phase
}

\author{
Henryk Wincel \\ Institute of Physical Chemistry, Polish Academy of Sciences, Warsaw, Poland
}

\begin{abstract}
Thermochemical data, $\Delta H^{o}{ }_{n}, \Delta S^{o}{ }_{n}$, and $\Delta G^{o}{ }_{n}$, for the hydration of protonated nucleic acid bases and protonated nucleosides have been experimentally studied by equilibrium measurements using an electrospray high-pressure mass spectrometer equipped with a pulsed ion-beam reaction chamber. For protonated nucleobases the hydration enthalpies were found to be similar for all studied systems and varied between 12.4-13.1 kcal/mol for the first and $11.2-11.5 \mathrm{kcal} / \mathrm{mol}$ for the second water molecule. While for protonated nucleosides the water binding enthalpies $(11.7-13.3 \mathrm{kcal} / \mathrm{mol})$ are very close to those for protonated nucleobases, the entropy values are "more negative." The structural and energetic aspects of hydrated ions are discussed in conjunction with the available theoretical data. (J Am Soc Mass Spectrom 2009, 20, 1900-1905) (C) 2009 American Society for Mass Spectrometry
\end{abstract}

$\mathrm{N}$ ucleic acid bases are amongst the primary building blocks of DNA and RNA, and water is generally considered to be their integral part. Hydration of nucleobases is crucially important for the structure, stability, and biologic functions of DNA [1, 2]. Interaction between the DNA constituents and water molecules is important for a better understanding of the mechanistic role of water molecules in conformational transitions and mechanisms of DNA's bioactivity. The effect of hydration of the DNA bases is very local and only a limited number of water molecules contribute to it significantly [1, 2]. Many studies on the gas-phase interactions of neutral and anionic forms of nucleic acid bases [3-13] and nucleosides [14] with water molecules have been performed theoretically. A few experimental studies have been carried out on hydration enthalpies [15], IR spectra [13], UV spectra [16], hydration dynamics [17] of DNA bases, ionization potentials [18], and metastable decay [19] of hydrated adenine and thymine cations. Much less attention has been paid to the hydration of protonated DNA components, although these forms are of considerable interest in view of their potential formation in radiation-induced damage of DNA and RNA, and interaction with a water environment. To our best knowledge, the stabilities of protonated adenine tautomers and their complexes with water molecules [20] have only been investigated computationally, while there have been some experimental and theoretical studies on the hydration of protonated and deprotonated forms of the four mononucleotides (dAMP, dCMP, dGMP, and dTMP) [21]. More recently,

Address reprint requests to Professor Henryk Wincel, Institute of Physical Chemistry, Polish Academy of Sciences, Kasprzaka 44/52, 01-224 Warsaw, Poland. E-mail: wincel@ichf.edu.pl the possible tautomeric forms of the monohydrated protonated uracil have been examined in the gas phase by using IR multiple-photon dissociation spectroscopy (IRMPD) in combination with computational study [22].

In this paper, we present the first experimental results on the energetics of hydration of protonated nucleic acid bases, NABs (uracil, Ura; thymine, Thy; adenine, Ade; and hypoxanthine, Hyp), and protonated nucleosides, NSDs (uridine, Urd; thymidine, Thd; adenosine, Ado; and inosine, Ino). These results were obtained from high-pressure mass spectrometry equilibria measurements in the gas phase. Previously, we measured the energetics of hydration of protonated and deprotonated amino acids [23-25].

\section{Experimental}

All experiments were performed on a high-pressure (HP) mass spectrometer using a pulsed ion-beam ESI ion source (Figure 1), which has been previously described in detail elsewhere [23]. Briefly, ions were generated by electrospray from a silica capillary (ESC) at the room temperature. The solution containing 2.0 $\mathrm{mM}$ NAB or NSD in a water/methanol (10/90) mixture was supplied to the capillary by a syringe pump at a rate of $0.8 \mu \mathrm{L} / \mathrm{min}$. The samples studied were purchased from Aldrich Chemical Co. (Steinheim, Germany) and used without further purification.

The clustered ions were desolvated by a dry nitrogen gas counter current and in a heated pressure-reducing capillary (PRC) through which they were introduced into the fore-chamber $(\mathrm{FC})$, and then deflected toward a 3-mm orifice in the interface plate (IP) leading to the reaction chamber (RC). Ions drifting across the RC toward the exit slit (ES) under the influence of a weak 


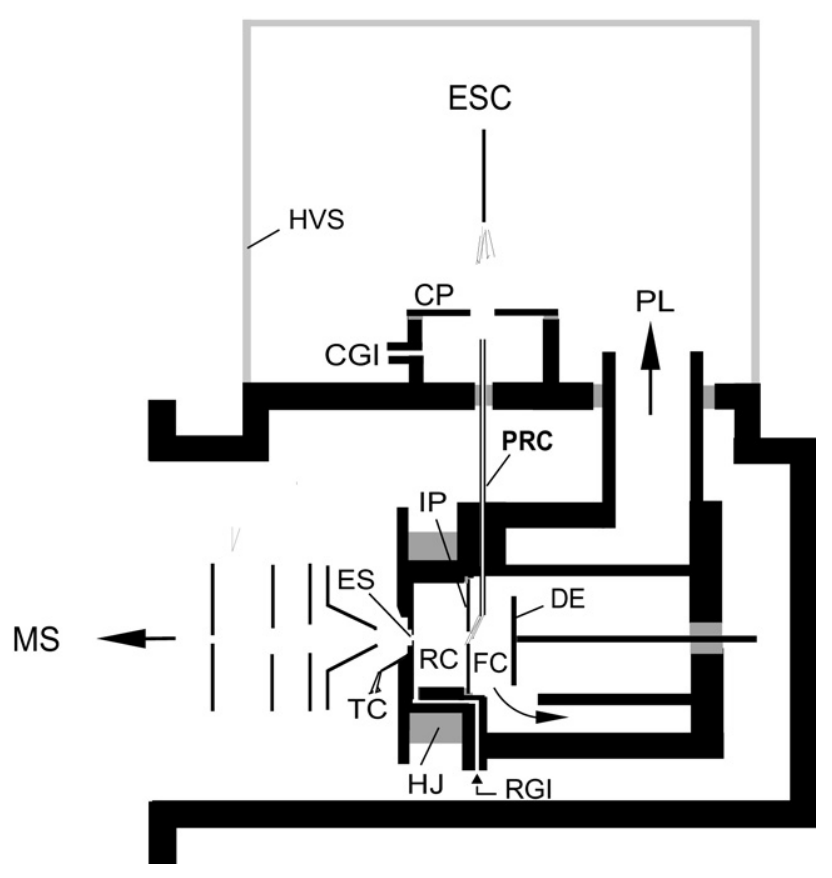

Figure 1. Scheme of the high-pressure ion source with pulsed ion beam: (ESC) electrospray capillary; (HVS) high voltage shield; (CP) curtain plate; (CGI) curtain gas inlet; (PL) pumping lead; (PRC) pressure reducing capillary; (FC) fore-chamber; (DE) deflection electrode; (IP) interface plate; (RC) reaction chamber; (RGI) reaction gas inlet; (TC) thermocouple; (ES) ion exit slit; (HJ) electrically heated jacket.

electric field ( $2 \mathrm{~V} / \mathrm{cm}$ at $10 \mathrm{mbar}$ ) were hydrated and reached equilibrium before being sampled to the mass analysis section of the mass spectrometer.

Mass spectra were registered with continuous ion sampling, while for equilibrium determination the ion beam was injected into the RC in a pulsing mode by applying short pulses $(+50 \mathrm{~V}, 90 \mu \mathrm{s})$ to the deflection electrode (DE) with repetition of $1 \mathrm{~ms}$. The latter mode of operation allows for measurements of the arrival time distribution (ATD) of the ions across the RC.

The reagent gas mixture consisting of pure $\mathrm{N}_{2}$ as the carrier gas at about 10 mbar and a known partial pressure of water vapor (0.02-0.25 mbar) was supplied to the RC via the heated reactant gas inlet (RGI) at a flow rate of $\sim 100 \mathrm{~mL} / \mathrm{min}$. The pressure was measured with an MKS capacitance manometer attached near the inlet of the RGI. The amount of water introduced into the $\mathrm{N}_{2}$ gas flow was kept constant throughout the temperature-dependent measurements of the equilibrium constants. Water concentrations were controlled continuously with a Delta OHM calibrated temperature and humidity transmitter (type DO 9861T; Caselle di Selvazzano, Italy) inserted into the carrier gas flow line. The RC temperature was monitored by an iron-constantan thermocouple (TC) which was embedded close to the ion exit slit; the temperature can be varied between 300 and $570 \mathrm{~K}$ by electrical heaters.

The enthalpy change, $\Delta H^{o}{ }_{n}$, and the entropy change, $\Delta S^{o}{ }_{n}$, for the reaction (eq 1 )

$$
\begin{aligned}
& \mathrm{BH}^{+} \cdot\left(\mathrm{H}_{2} \mathrm{O}\right)_{n-1}+\mathrm{H}_{2} \mathrm{O}<=>\mathrm{BH}^{+} \cdot\left(\mathrm{H}_{2} \mathrm{O}\right)_{n} \\
& \mathrm{~B}=\text { NAB or NSD }
\end{aligned}
$$

were obtained from temperature-dependent measurements of the equilibrium constants, $K_{n-1, n}$ (eq 2)

$$
K_{n-1, n}=\left(I_{n} \cdot 1000 / I_{n-1} \cdot P\right)
$$

where $I_{n}$ and $I_{n}-{ }_{1}$ are recorded ATD peak areas of $\mathrm{BH}^{+} \cdot\left(\mathrm{H}_{2} \mathrm{O}\right)_{n}$ and $\mathrm{BH}^{+} \cdot\left(\mathrm{H}_{2} \mathrm{O}\right)_{n-1}$, respectively, and $P$ is the known partial pressure of the water (in mbar). Equilibrium attainment was checked by comparing the ATDs of the reactant and product ions (eq 1), and testing the ion intensity ratio of $\left[\mathrm{BH}^{+} \cdot\left(\mathrm{H}_{2} \mathrm{O}\right)_{n} / \mathrm{BH}^{+} \cdot\left(\mathrm{H}_{2} \mathrm{O}\right)_{n}-{ }_{1}\right]$ as a function of ion residence time, as has been described previously $[23,25]$. The enthalpy and entropy changes were obtained from van't Hoff plots, based on eq 3, while the standard free-energy, $\Delta G^{o}{ }_{n}$, was obtained from $\Delta G_{n}^{o}=$ $\Delta H_{n}^{o}-T \Delta S_{n}^{o}$.

$$
\text { In } K_{n-1, n}=\left(\Delta S_{n}^{o} / R\right)-\left(\Delta H_{n}^{o} / R T\right)
$$

The weighted least-squares fitting procedure was used to obtain the slopes and intercepts of each line.

\section{Results}

Plots of the logarithm of the equilibrium constants, $K_{n-1, n}$, versus the reciprocal temperature for the systems studied are shown in Figures 2 and 3. Thermochemical data derived from these van't Hoff plots are presented in Table 1. Our inability to measure the enthalpies for further hydration steps is a consequence of their very low ion intensities at the lowest temperatures available in the RC. The reported $\Delta H^{o}{ }_{n}$ and $\Delta S^{o}{ }_{n}$ values are the averages of at least three measurements and the error limits correspond to the standard deviations of linearsquares fit. These values reflect only statistical fluctuations. The systematic error may be present and the absolute error from an unknown true value could be considerably larger.

The results in Table 1 show that the hydration enthalpies of $\mathrm{NABH}^{+}$and $\mathrm{NSDH}^{+}$are similar and very close to the experimental $-\Delta H^{o}{ }_{1}$ values $(10.5-13.5$ $\mathrm{kcal} / \mathrm{mol}$ ) obtained by Bowers and coworkers for protonated nucleotides [21].

\section{Discussion}

\section{Uracil and Thymine and Their Nucleosides}

Previous theoretical investigations [26-29] of different tautomers of neutral uracil and thymine indicate that the keto form, $\mathbf{1}$, is at least $11 \mathrm{kcal} / \mathrm{mol}$ more stable than other possible structures of these two bases. The most basic site in this structure is at the $\mathrm{O}_{8}$ atom with a proton affinity (PA) of $205.5 \mathrm{kcal} / \mathrm{mol}$ for uracil and $207.0 \mathrm{kcal} / \mathrm{mol}$ for thymine, and is more basic by about $6.9-8.4 \mathrm{kcal} / \mathrm{mol}$ than the $\mathrm{O}_{7}$ atom $[3,26]$. Protonations 

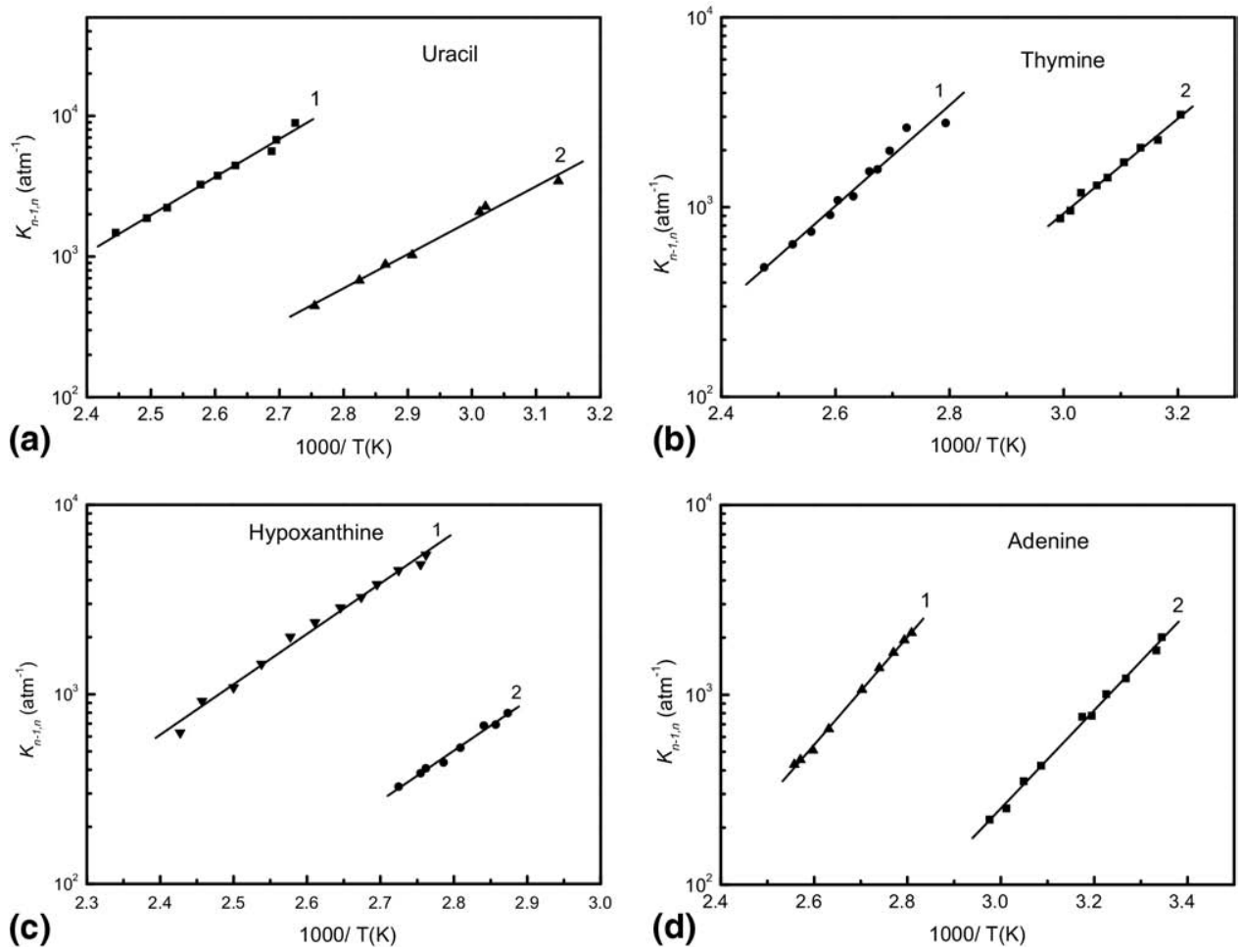

Figure 2. van't Hoff plots of equilibrium constants for the gas-phase reactions $\mathrm{BH}^{+} \cdot\left(\mathrm{H}_{2} \mathrm{O}\right)_{n-1}+\mathrm{H}_{2} \mathrm{O}$ $<=>\mathrm{BH}^{+} \cdot\left(\mathrm{H}_{2} \mathrm{O}\right)_{n}$, where B equals (a) Ura; (b) Thy; (c) Hyp; (d) Ade. The numbers shown in the figures correspond to the value of $n$.

at the $\mathrm{N}$ and $\mathrm{C}$ atoms in $\mathbf{1}$ are less favorable than at the $\mathrm{O}$ atoms. According to in vacuo calculations [30], the ratio of equilibrium constants of the formation of protonated uracil- $\mathrm{O}_{8}$ and uracil- $\mathrm{O}_{7}$ is $\sim 10^{8}$, while in an aqueous medium this ratio is predicted to be in the range $(1.4-2) \times 10^{4}$. This may suggest that 1 a would be the predominant structure formed by electrospray and in equilibrium measurements. However, the experiments performed in the gas phase by using IR-MPD spectroscopy show that this structure should be present

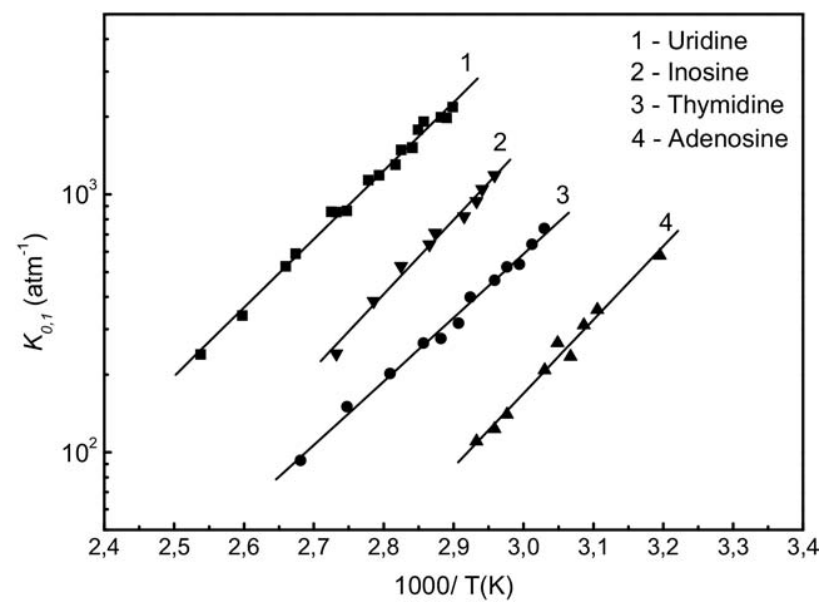

Figure 3. van't Hoff plots of equilibrium constants for the gas-phase reactions $\mathrm{BH}^{+} \cdot\left(\mathrm{H}_{2} \mathrm{O}\right)_{n-1}+\mathrm{H}_{2} \mathrm{O}<=>\mathrm{BH}^{+} \cdot\left(\mathrm{H}_{2} \mathrm{O}\right)_{n}$. Compounds $\mathrm{B}$ are given in the figure. as a minor fraction, and an enol form, $\mathbf{1 d}$, a dominant species of $\mathrm{UraH}^{+}$and $\mathrm{ThyH}^{+}$generated by electrospray from aqueous solutions at a capillary temperature of $473 \mathrm{~K}$ [31]. The enol-1d forms are more stable (1.0-2.7 $\mathrm{kcal} / \mathrm{mol}$ ) than the respective 1a tautomers [26, 29, 31]. While the 1a form can be created by direct protonation of $\mathbf{1}$, the mechanism of formation of the enolic-1d form under electrospray conditions is not clear. The gasphase $1 \mathbf{1 a} \rightarrow \mathbf{1 d}$ interconversion via the 1,3 proton transfer requires an energy barrier in excess of $35-40$

Table 1. Experimental enthalpies, entropies, and free energies for the hydration of nucleic acid bases and nucleosides ${ }^{a}$

\begin{tabular}{lcccc}
\hline \multicolumn{1}{c}{ Ion } & $n$ & $\begin{array}{c}-\Delta H^{O} \\
(\mathrm{kcal} / \mathrm{mol})\end{array}$ & $\begin{array}{c}-\Delta S^{O}{ }_{n} \\
(\mathrm{cal} / \mathrm{mol} \mathrm{K})\end{array}$ & $\begin{array}{c}-\Delta G^{O}{ }_{n} \\
(\mathrm{kcal} / \mathrm{mol})^{\mathrm{b}}\end{array}$ \\
\hline \hline $\mathrm{UraH}^{+}$ & 1 & $12.4(0.5)$ & $15.8(1.3)$ & $7.7(0.9)$ \\
& 2 & $11.2(0.5)$ & $18.4(1.4)$ & $5.7(0.9)$ \\
$\mathrm{ThyH}^{+}$ & 1 & $13.0(0.5)$ & $20.0(0.9)$ & $7.0(0.8)$ \\
& 2 & $11.5(0.4)$ & $21.2(0.9)$ & $5.2(0.7)$ \\
$\mathrm{AdeH}^{+}$ & 1 & $13.1(0.4)$ & $21.8(1.3)$ & $6.6(0.8)$ \\
& 2 & $11.2(0.4)$ & $22.4(0.8)$ & $4.5(0.7)$ \\
$\mathrm{HypH}^{+}$ & 1 & $12.6(0.3)$ & $17.4(0.8)$ & $7.4(0.5)$ \\
& 2 & $11.2(0.4)$ & $19.0(1.2)$ & $5.5(0.4)$ \\
$\mathrm{UrdH}^{+}$ & 1 & $12.2(0.3)$ & $20.0(0.7)$ & $6.2(0.5)$ \\
$\mathrm{ThdH}^{+}$ & 1 & $11.7(0.3)$ & $22.3(0.9)$ & $5.1(0.6)$ \\
$\mathrm{Ado} \mathrm{H}^{+}$ & 1 & $13.3(0.6)$ & $29.2(2.0)$ & $4.6(1.2)$ \\
InoH $^{+}$ & 1 & $13.2(0.6)$ & $25.0(1.6)$ & $5.8(0.9)$ \\
\hline
\end{tabular}

Standard pressure is 1000 mbar.

aErrors are listed in parentheses.

${ }^{\mathrm{b}} \Delta G^{O}{ }_{n}$ at $297 \mathrm{~K}$. 
$\mathrm{kcal} / \mathrm{mol}[29,31]$ to be overcome, making it energetically inaccessible at thermal energies. Similarly, the water-catalyzed isomerization of $\mathbf{1 a}$ into $\mathbf{1 d}$ by 1,3 proton transfer converting $\mathbf{1 b} \rightarrow \mathbf{1} \mathbf{e}$ is relatively high in energy $(16.6 \mathrm{kcal} / \mathrm{mol})$, and is also not expected to occur in the collision cell [22]. Note that $\mathbf{1 b}$ is more stable than $1 \mathrm{e}$ and $1 \mathrm{f}$ by 1.7 and $3.1 \mathrm{kcal} / \mathrm{mol}$ [22], respectively. Therefore, it was suggested $[22,31]$ that the enolic tautomers of $\mathrm{UraH}^{+}$and $\mathrm{ThyH}^{+}$are formed upon ion generation by electrospray, either in solution or within the electrospray droplets.

When the $\mathrm{UraH}^{+}$ions from electrospray are hydrated in a collision cell, the mixture of the $\mathbf{1 b}, \mathbf{1 e}$, and 1f isomers are observed by the IR-MPD spectroscopy, and the existence of the enolic forms, $\mathbf{1 e}$ and $\mathbf{1 f}$, is attributed to the resonance of two Kekule structures [22]. This finding is an indication for the formation of protonated keto and enolic tautomers of uracil and thymine, and their hydrated clusters under our experimental conditions.
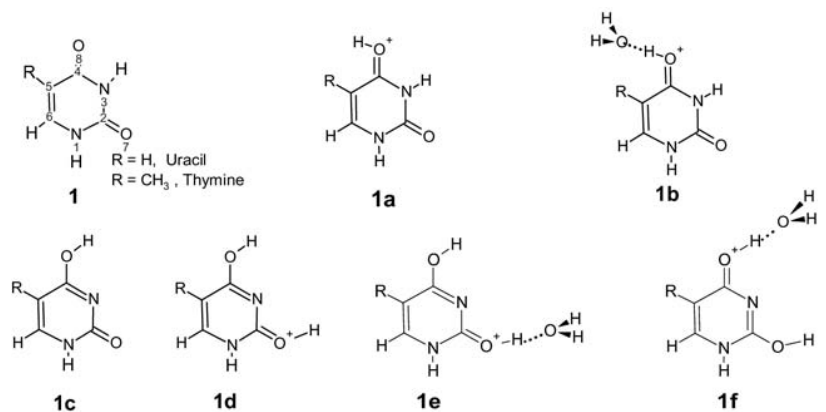

The $-\Delta G^{o}{ }_{298}$ value of $7.7 \pm 0.9 \mathrm{kcal} / \mathrm{mol}$ (Table 1) obtained in the present experiments for $\mathrm{UraH}^{+} \cdot \mathrm{H}_{2} \mathrm{O}$ is close to the value, $8.2 \mathrm{kcal} / \mathrm{mol}$, calculated [22] on the basis of formation of $\mathbf{1 e}$ from 1d, and much lower than that of $11.2 \mathrm{kcal} / \mathrm{mol}$ predicted for the addition of $\mathrm{H}_{2} \mathrm{O}$ to $1 \mathrm{a}$ to yield $\mathbf{1 b}$, thus suggesting that the enolic forms are the dominant ionic species of a mixture of the structures $\mathbf{1 a}$ and $\mathbf{1 d}$ involved in the equilibrium measurement for the association of $\mathrm{UraH}^{+}$with $\mathrm{H}_{2} \mathrm{O}$. These results are in line with the structural assignments based on the IR spectroscopy $[22,31]$. Taking into account similarity of the IR-spectra [22, 23] and the thermochemical properties (Table 1) obtained for $\mathrm{UraH}^{+}$and $\mathrm{ThyH}^{+}$, the same conclusion can also be related to $\mathrm{ThyH}^{+}$. Considering the higher stability of $\mathbf{1 e}$ than $\mathbf{1 f}$, one can expect that the relative abundance of $1 \mathbf{e}$ should be considerably larger than that of $\mathbf{1 f}$, and the second water molecule is most likely added to $1 \mathbf{e}$ via $\mathrm{O}_{8} \mathrm{H}$.

Interestingly, in the conventional anionic complex $\mathrm{Ura}^{-} \cdot \mathrm{H}_{2} \mathrm{O}$, the water binding is strongest at the uracil $\mathrm{O}_{8}$ site [6] and, calculated at the UMBPT (2) + ZPE level of theory, the $\mathrm{O}_{8} \cdots \mathrm{HOH}$ hydrogen bond energy, 12.6 $\mathrm{kcal} / \mathrm{mol}$, is very close to the experimental $\Delta H^{\circ}{ }_{1}$ value of $12.4 \mathrm{kcal} / \mathrm{mol}$ for $\mathrm{UraH}^{+} \cdot\left(\mathrm{H}_{2} \mathrm{O}\right)$, Table 1 . Similarly, the measured $\Delta H^{o}{ }_{1}$ value, $13.0 \mathrm{kcal} / \mathrm{mol}$, for $\mathrm{ThyH}^{+}$. $\left(\mathrm{H}_{2} \mathrm{O}\right)$, is consistent with the hydration energies, 12.4 and $12.7 \mathrm{kcal} / \mathrm{mol}$, calculated [10] at the B3LYP/ $\mathrm{DZP}++$ level for water binding in Thy ${ }^{-} \cdot \mathrm{H}_{2} \mathrm{O}$ at the most stable positions, $\mathrm{O}_{8}$ and between the $\mathrm{O}_{8}$, and $\mathrm{N}_{3} \mathrm{H}$ bonds, respectively. Furthermore, in the same study, the calculated binding strengths between Thy ${ }^{-}$and two water molecules, $23.7 \mathrm{kcal} / \mathrm{mol}$, in the most stable dihydrate Thy ${ }^{-} \cdot\left(\mathrm{H}_{2} \mathrm{O}\right)_{2}$, are close to the sum of hydration energies $(24.5 \mathrm{kcal} / \mathrm{mol})$ measured for the first and second $\mathrm{H}_{2} \mathrm{O}$ molecules in the ThyH ${ }^{+} \cdot\left(\mathrm{H}_{2} \mathrm{O}\right)_{2}$ complex (Table 1).

A comparison of the hydration free-energy values $\left(-\Delta G_{n}^{o}\right)$ in Table 1 indicates that the $\mathrm{H}_{2} \mathrm{O}$ molecules bind to $\mathrm{UraH}^{+}$slightly more strongly than to $\mathrm{ThyH}^{+}$. Although the differences between these values are within the range of the experimental uncertainty, the slightly lower binding strengths for ThyH ${ }^{+} \cdot\left(\mathrm{H}_{2} \mathrm{O}\right)_{n}=1,2$ than the corresponding $\mathrm{UraH}^{+} \cdot\left(\mathrm{H}_{2} \mathrm{O}\right)_{n}=1,2$ can be accounted for by the somewhat higher PA of Thy (210.5 $\mathrm{kcal} / \mathrm{mol})$ than that of Ura $(208.6 \mathrm{kcal} / \mathrm{mol})$. As previously [32] stated, the $\mathrm{XH}^{+} \ldots \mathrm{Y}$ hydrogen bond decreases as $\triangle \mathrm{PA}=\mathrm{PA}(\mathrm{X})-\mathrm{PA}(\mathrm{Y})$ increases. Such correlations between hydrogen-bond energies and proton affinities (or gas-phase basicities) are well-documented in the literature for neutral and ionic hydrogen bonds [5].

Similarly to uracil and thymine, the calculations [33] at the B3LYP/6-31G* level of theory predict that the $\mathrm{O}_{8}\left(\mathrm{C}_{5}\right)$ position is the most preferred protonation site for the most stable uridine and thymidine tautomers, 2, and this position is likely to be the most favorable for water binding, $\mathbf{2 a}$.
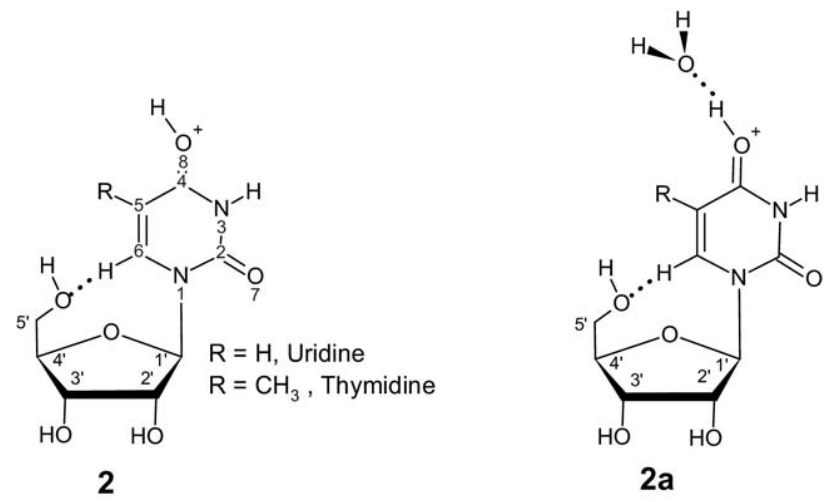

\section{Adenine and Adenosine}

In adenine structure 3 , the $\mathrm{N}_{1}$ atom is the most basic site, $\mathrm{PA}=224.4 \mathrm{kcal} / \mathrm{mol}$, and this position is expected to be greatly favored for protonation by electrospray ionization over the second most basic site at $\mathrm{N}_{3}, \mathrm{PA}=$ $222.7 \mathrm{kcal} / \mathrm{mol}$, and the third at the $\mathrm{N}_{7}$ atom, $\mathrm{PA}=$ $216.1 \mathrm{kcal} / \mathrm{mol}$ [20]. The calculations [20, 29] predict that $3 \mathbf{a}$ is the most stable protonated form of adenine. Also, the authors [20] show that the most stable complexes of $\mathrm{AdeH}^{+} \cdot\left(\mathrm{H}_{2} \mathrm{O}\right)_{n=1,2}$ are formed when the first $\mathrm{H}_{2} \mathrm{O}$ molecule interacts with 3a at the $\mathrm{N}_{1} \mathrm{H}$ and $\mathrm{N}_{10} \mathrm{H}$ sites (Structure $\mathbf{3 b}$ ) and the second one forms a hydrogen bond to the $\mathrm{N}_{9} \mathrm{H}$ position (Structure 3c). At equilibrium, this structure is expected to constitute about $97 \%$ of the $\mathrm{AdeH}^{+} \cdot\left(\mathrm{H}_{2} \mathrm{O}\right)_{2}$ clusters. 


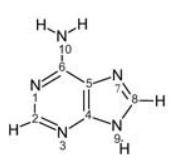

3

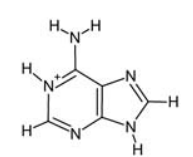

3a

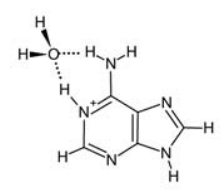

3b

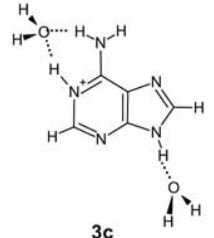

The values of enthalpy, $14.6 \mathrm{kcal} / \mathrm{mol}$, and freeenergy, $6.2 \mathrm{kcal} / \mathrm{mol}$, calculated [20] for the dissociation of $\mathbf{3 b}$ to $\mathbf{3 a}$ are in reasonable agreement with the corresponding experimental values of $13.1 \pm 0.4 \mathrm{kcal} /$ $\mathrm{mol}$ and $6.6 \pm 0.8 \mathrm{kcal} / \mathrm{mol}$ for the $\mathrm{AdeH}^{+} \cdot\left(\mathrm{H}_{2} \mathrm{O}\right)$ complex (Table 1). Also, in the $\mathrm{AdeH}^{+} \cdot\left(\mathrm{H}_{2} \mathrm{O}\right)_{2}$ case, the calculated [20] enthalpy, $10.8 \mathrm{kcal} / \mathrm{mol}$, and free-energy, $3.6 \mathrm{kcal} / \mathrm{mol}$, for the dissociation $3 \mathrm{c} \rightarrow 3 \mathbf{b}$ are in good agreement with the measured values of $11.2 \pm 0.4$ $\mathrm{kcal} / \mathrm{mol}$, and $4.5 \pm 0.7 \mathrm{kcal} / \mathrm{mol}$, respectively. For an alternative structure of the $\mathrm{AdeH}^{+} \cdot\left(\mathrm{H}_{2} \mathrm{O}\right)_{2}$ cluster in which the protonation site is $\mathrm{N}_{3}$ and one $\mathrm{H}_{2} \mathrm{O}$ molecule is hydrogen-bonded to $\mathrm{AdeH}^{+}$via $\mathrm{N}_{3} \mathrm{H}$ and $\mathrm{N}_{9} \mathrm{H}$ and the other water via $\mathrm{N}_{10} \mathrm{H}$, the calculated [20] binding enthalpy and free-energy values are $14.1 \mathrm{kcal} / \mathrm{mol}$ and $5.7 \mathrm{kcal} / \mathrm{mol}$ for the first $\mathrm{H}_{2} \mathrm{O}$ molecule and $9.8 \mathrm{kcal} /$ $\mathrm{mol}$ and $2.9 \mathrm{kcal} / \mathrm{mol}$ for the second water, respectively. From this comparison, it follows that the $3 \mathrm{c}$ structure is prevalent in our measurements.

In the case of adenosine, the entropy change $-\Delta S^{o}{ }_{1}$ value is relatively high compared with that of the $\mathrm{Ade}^{+} \cdot\left(\mathrm{H}_{2} \mathrm{O}\right)$ complex, Table 1 . This suggests that the $\mathrm{H}_{2} \mathrm{O}$ molecule in $\mathrm{AdoH}^{+} \cdot\left(\mathrm{H}_{2} \mathrm{O}\right)$ is bound more tightly than in the $\mathrm{Ade}^{+} \cdot\left(\mathrm{H}_{2} \mathrm{O}\right)$ complex. A possible explanation for this situation could be that the water molecule in $\mathrm{AdoH}^{+} \cdot\left(\mathrm{H}_{2} \mathrm{O}\right)$ is involved in the intermolecular $\mathrm{H}$-bonded interaction with both the adenine and ribose subsystems. High-level theoretical calculations [34] show that in contrast to adenine, in adenosine, 4, the $\mathrm{N}_{3}$ atom is the most favorable site for protonation. Furthermore, these results suggest that the two most stable structures are formed when a strong intramolecular hydrogen bond appears between $\mathrm{N}_{3} \mathrm{H}$ and $\mathrm{O}_{5^{\prime}}, 4 \mathbf{a}$, or between $\mathrm{N}_{3} \mathrm{H}$ and $\mathrm{O}_{2^{\prime}}, 4 \mathbf{b}$.

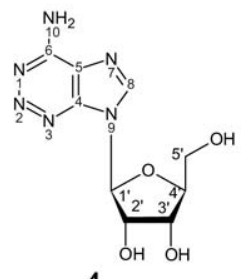

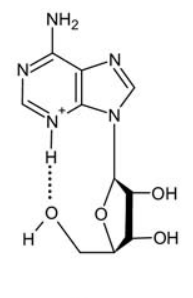

$4 a$

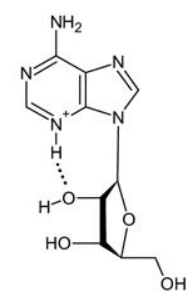

4b

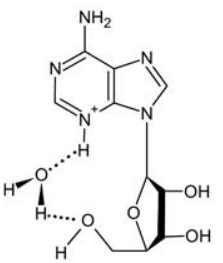

$4 c$

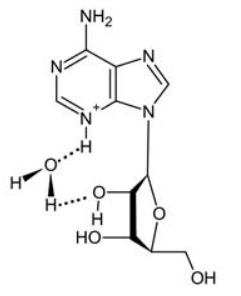

4d
These tautomers are very close in energy (within less than $0.7 \mathrm{kcal} / \mathrm{mol}$ ), and more stable (by about 8-15 $\mathrm{kcal} / \mathrm{mol}$ ) than those protonated on the $\mathrm{N}_{1}$ or $\mathrm{N}_{7}$ atoms [34]. It is reasonable to assume that both tautomers, $4 a$ and $\mathbf{4 b}$, coexist in our experiments. In these complexes, the water molecule could be included between the bonds $\mathrm{N}_{3} \mathrm{H} \cdots \mathrm{O}_{5^{\prime}}(4 \mathbf{a})$ or $\mathrm{N}_{3} \mathrm{H} \cdots \mathrm{O}_{2^{\prime}}(4 \mathbf{b})$ leading to the formation of hydrated structures $4 \mathrm{c}$ or $4 \mathrm{~d}$, respectively.

\section{Hypoxanthine}

The two ketonic tautomers of hypoxanthine, $\mathrm{N}_{7} \mathrm{H}$ and $\mathrm{N}_{9} \mathrm{H}$, are energetically the most stable (for both forms a hydrogen is attached at the $\mathrm{N}_{1}$ site). The $\mathrm{N}_{7} \mathrm{H}$ form is predicted to be more stable than $\mathrm{N}_{9} \mathrm{H}$ by $0.8 \mathrm{kcal} / \mathrm{mol}$ $[13,35]$. In the gas phase, the $\mathrm{N}_{7} \mathrm{H}$ form was calculated $[7,13,36]$ to be $\sim 64 \%$, and the $\mathrm{N}_{9} \mathrm{H}$ form would be about $36 \%$, while the enol- $\mathrm{N}_{9} \mathrm{H}$ tautomer would be only $0.2 \%$. In hydrated form, the $\mathrm{N}_{9} \mathrm{H}$ tautomer, 5 , is predicted [7] to be the predominant structure in which the $\mathrm{N}_{7}$ atom is the most basic site $(\mathrm{PA}=219.6 \mathrm{kcal} / \mathrm{mol}$ [35]. The next most basic site is $\mathrm{O}_{10}(\mathrm{PA}=213.9$ $\mathrm{kcal} / \mathrm{mol})$. Therefore, when hypoxanthine is protonated in an aqueous solution by electrospray, the formation of 5a should be favored. This structure is more stable than the $\mathrm{N}_{9} \mathrm{H}$ isomers protonated at the $\mathrm{O}_{10}$ and $\mathrm{N}_{3}$ atoms by 5.9 and $15.1 \mathrm{kcal} / \mathrm{mol}$, respectively [35]. The first $\mathrm{H}_{2} \mathrm{O}$ molecule is likely to add to the 5a structure between the $\mathrm{N}_{7} \mathrm{H}$ and $\mathrm{O}_{10}$ bonds (Complex $5 \mathbf{b}$ ), while the second water molecule in the $\mathrm{HypH}^{+} \cdot\left(\mathrm{H}_{2} \mathrm{O}\right)_{2}$ cluster can be placed between $\mathrm{N}_{1} \mathrm{H}$ and $\mathrm{O}_{10}$. This position has the highest calculated $[7,13]$ interaction energy, $10.18 \mathrm{kcal} /$ mol, in the neutral complex, Hyp $\cdot\left(\mathrm{H}_{2} \mathrm{O}\right)$, of the keto$\mathrm{N}_{9} \mathrm{H}$ form.

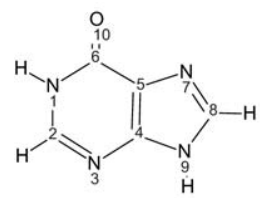

5

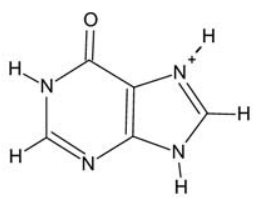

$5 a$

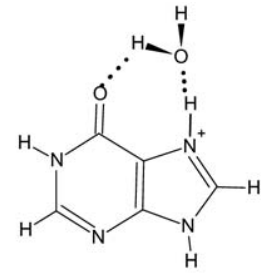

$5 b$
The measured binding energies $\left(-\Delta H_{1,2}^{o}\right)$ for $\mathrm{HypH}^{+}$. $\left(\mathrm{H}_{2} \mathrm{O}\right)_{n=1,2}$ are similar to those of $\mathrm{AdeH}^{+} \cdot\left(\mathrm{H}_{2} \mathrm{O}\right)_{n=1,2}$, but the $-\Delta G_{1,2}^{o}$ values of $\mathrm{HypH}^{+} \cdot\left(\mathrm{H}_{2} \mathrm{O}\right)_{n=1,2}$ are somewhat higher than the corresponding values of $\mathrm{AdeH}^{+}$. $\left(\mathrm{H}_{2} \mathrm{O}\right)_{n}=1,2$, which probably reflects the smaller PA of Hyp as compared with that of Ade.

Now no data are available for gas-phase protonation or enthalpies of the tautomers of inosine. Therefore, the suggestion of reactive sites for water interaction with $\mathrm{InoH}^{+}$seems to be very problematic.

\section{Conclusions}

In this work, noncovalent interactions between protonated nucleobases (uracil, thymine, adenine, and hypoxanthine) and nucleosides (uridine, thymidine, adeno- 
sine, and inosine) on the one hand, and water molecules on the other, have been investigated by pulsed highpressure mass spectrometry with electrospray ionization. The water binding energies of the first water molecule found for these systems in the present work are similar and very close to those of the protonated nucleotides obtained in another laboratory [21]. Interestingly, the water interaction energies for the protonated uracil and thymine are similar to those calculated $[6,10]$ for corresponding valence-bound anions of these bases. Considering the relative stabilities of protonated tautomers and favorable sites for interactions with water molecules, possible structures for $\mathrm{H}$-bonded complexes have been presented. In the case of uracil and thymine, the experimental findings support the spectroscopic observations $[22,31]$ that the keto $\rightarrow$ enol tautomerization of $\mathrm{UraH}^{+}$and $\mathrm{ThyH}^{+}$occurs under electrospray conditions. Computational studies of relative stabilities and IR photodissociation spectra of several complexes are now required to verify their structures.

\section{References}

1. Schneider, B.; Cohen, D.; Berman, H. M. Hydration of DNA Bases: Analysis of Crystallographic Data. Biopolymers 1992, 32, 725-750.

2. Schneider, B.; Berman, H. M. Hydration of the DNA Bases is Local. Biophys. J. 1995, 69, 2661-2669.

3. Chandra, A. K.; Nguyen, M. T.; Zeegers-Huyskens, T. Theoretical Study of the Interaction between Thymine and Water. Protonation and Deprotonation Enthalpies and Comparison with Uracil. J. Phys. Chem. A 1998, 102, 6010-6016.

4. Gu, J.; Leszczynski, J. A DFT Study of the Water-Assisted Intramolecular Proton Transfer in the Tautomers of Adenine. J. Phys. Chem. A 1999, 103, 2744-2750.

5. Chandra, A. K.; Nguyen, M. T.; Uchimaru, T.; Zeegers-Huyskens, T. Protonation and Deprotonation Enthalpies of Guanine and Adenine and Implications for the Structure and Energy of Their Complexes with Water: Comparison with Uracil, Thymine, and Cytosine. J. Phys. Chem. A 1999, 103, 8853-8860.

6. Dolgounitcheva, O.; Zakrzewski, V. G.; Ortiz, J. V. Anionic and Neutral Complexes of Uracil and Water. J. Phys. Chem. A 1999, 103, 7912-7917.

7. Shukla, M. K.; Leszczynski, J. Theoretical Study of Proton Transfer in Hypoxanthine Tautomers: Effects of Hydration. J. Phys. Chem. A 2000, 104, 3021-3027.

8. Kryachko, E. S.; Nguyen, M. T.; Zeegers-Huyskens, T. Theoretical Study of Uracil Tautomers. 2. Interaction with Water. J. Phys. Chem. A 2001, 105, 1934-1943.

9. Hanus, M.; Kabeláč, M.; Rejnek, J.; Ryjáček, F.; Hobza, P. Correlated Ab Initio Study of Nucleic Bases and Their Tautomers in the Gas Phase, in a Microhydrated Environment and in Aqueous Solution. Part 3. Adenine. J. Phys. Chem. B 2004, 108, 2087-2097.

10. Kim, S.; Wheeler, S. E.; Schaefer H. F. III. Microsolvation Effects on the Electron Capturing Ability of Thymine: Thymine-Water Clusters. J. Chem. Phys. 2006, 124, 204310-204318.

11. Kabeláč, M.; Hobza, P. Hydration and Stability of Nucleic Acid Bases and Bases Pairs. Phys. Chem., Chem. Phys. 2007, 9, 903-917.

12. Desfrançois, C.; Abdoul-Carime, H.; Schermann, J. P. Electron Attachment to Isolated Nucleic Acid Bases. J. Chem. Phys. 1996, 104, 7792-7794.

13. Ramaekers, R.; Maes, G.; Adamowicz, L.; Dkhissi, A. Matrix-Isolation FT-IR Study and Theoretical Calculations of the Vibrational, Tauto- meric, and H-Bonding Properties of Hypoxanthine. J. Mol. Struct. 2001, 560, 205-221.

14. Alcolea Palafox, M.; Iza, N.; De la Fuente, M.; Navarro, R. Simulation of the First Hydration Shell of Nucleosides D4T and Thymidine: Structures Obtained Using MP2 and DFT Methods. J. Phys. Chem. B 2009, 113, 2458-2476.

15. Sukhodub, L. F. Interactions and Hydration of Nucleic Acid Bases in a Vacuum. Experimental study. Chem. Rev. 1987, 87, 589-606.

16. Piuzzi, F.; Mons, M.; Dimicoli, I.; Tardivel, B.; Zhao, Q. Ultraviolet Spectroscopy and Tautomerism of the DNA Base Guanine and Its Hydrate Formed in a Supersonic Jet. Chem. Phys. 2001, 270, 205-214.

17. Pal, S. K.; Peon, J.; Zewail, A. H. Ultrafast Decay and Hydration Dynamics of DNA Bases and Mimics. Chem. Phys. Lett. 2002, 363, 57-63.

18. Kim, S. K.; Lee, W.; Herschbach, D. R. Cluster Beam Chemistry: Hydration of Nucleic Acid Bases; Ionization Potentials of Hydrated Adenine and Thymine. J. Phys. Chem. 1996, 100, 7933-7937.

19. Kim, N. J.; Kim, Y. S.; Leong, G.; Ahn, T. K.; Kim, S. K. Hydration of DNA Base Cations in the Gas Phase. Int. J. Mass Spectrom. 2002, 219, 11-21.

20. Tureček, F.; Chen, X. Protonated Adenine: Tautomers, Solvated Clusters, and Dissociation Mechanisms. J. Am. Soc. Mass Spectrom. 2005, 16, 1713-1726.

21. Liu, D.; Wyttenbach, T.; Bowers, M. T. Hydration Mononucleotides. J. Am. Chem. Soc. 2006, 128, 15155-15163.

22. Bakker, J. M.; Sinha, R. K.; Besson, T.; Brgnara, M.; Tosi, P.; Salpin, J.-Y.; Maître, P. Tautomerism of Uracil Probed Via Infrared Spectroscopy of Singly Hydrated Protonated Uracil. J. Phys. Chem. A 2008, 112, 12393 12400 .

23. Wincel, H. Hydration of Gas-Phase Protonated Alkylamines, Amino Acids, and Dipeptides Produced by Electrospray. Int. J. Mass Spectrom. 2006, 251, 23-31.

24. Wincel, H. Hydration Energies of Protonated Amino Acids. Chem. Phys. Lett. 2007, 439, 157-161.

25. Wincel, H. Hydration Energies of Deprotonated Amino Acids from Gas Phase Equilibria Measurements. J. Am. Soc. Mass Spectrom. 2008, 19, 1091-1097.

26. Wolken, J. K.; Tureček, F. Proton Affinity of Uracil. A Computational Study of Protonated Sites. J. Am. Soc. Mass Spectrom. 2000, 11, 1065-1071.

27. Kryachko, E. S.; Nguyen, M. T.; Zeegers-Huyskens, T. Theoretical Study of Tautomeric Forms of Uracil. 1. Relative Order of Stabilities and Their Relation to Proton Affinities and Deprotonation Enthalpies. J. Phys. Chem. A 2001, 105, 1288-1295.

28. Forde, G. K.; Forde, A. E.; Hill, G.; Ford, A.; Nazario, A.; Leszczynski, J. Comprehensive Study of the Effects of Methylation on Tautomeric Equilibria of Nucleic Acid Bases. J. Phys. Chem. B 2006, 110, 1556415571.

29. Wu, R.; McMahon, T. B. Investigation of Proton Transport Tautomerism in Clusters of Protonated Nucleic Acid Bases (Cytosine, Uracil, Thymine, and Adenine) and Ammonia by High-Pressure Mass Spectrometry. J. Am. Chem. Soc. 2007, 129, 569-580.

30. Ilich, P.; Hemann, C. F.; Hille, R. Molecular Vibrations of Solvated Uracil. Ab Initio Reaction Field Calculations and Experiment. J. Phys. Chem. B 1997, 101, 10923-10938.

31. Salpin, J.-Y.; Guillaumont, S.; Tortajada, J.; MacAleese, L.; Lemaire, J. Maitre, P. Infrared Spectra of Protonated Uracil, Thymine, and Cytosine. Chem. Phys. Chem. 2007, 8, 2235-2244.

32. Meot-Ner, M. The Ionic Hydrogen Bond and Ion Solvation. 2. Solvation of Onium Ions by One to Seven $\mathrm{H}_{2} \mathrm{O}$ Molecules. Relations between Monomolecular, Specific, and Bulk Hydration. J. Am. Chem. Soc. 1984, 106, 1265-1272.

33. Mezzache, S.; Aves, S.; Pepe, C; Quelquejeu, M; Fournier, F; Valery, J.-M.; Tabet, J.-C. Proton Affinity Ladder for Uridine and Analogs: Influence of the Hydroxyl Group on the Sugar Ring Conformation. J. Mass Spectrom. 2005, 40, 722-730.

34. Touboul, D.; Bouchoux, G; Zenobi, R. Gas-Phase Protonation Thermochemistry of Adenosine. J. Phys. Chem. B 2008, 112, 11716-11725.

35. Sun, X.; Lee, J. K. Acidity and Proton Affinity of Hypoxanthine in the Gas Phase Versus in Solution: Intrinsic Reactivity and Biological Implications. J. Org. Chem. 2007, 72, 6548-6555.

36. Costas M. E.; Acevedo-Chavez, R. Density Functional Study of the Neutral Hypoxanthine Tautomeric Forms. J. Phys. Chem. A 1997, 101, 8309-8318. 